\title{
Experimental Analysis of the Arrays of Macro Fiber Composite Patches for Rotational Piezoelectric Energy Harvesting from a Shaft
}

\author{
Piotr Micek and Dariusz Grzybek *(D) \\ Faculty of Mechanical Engineering and Robotics, AGH University of Science and Technology, Al. Mickiewicza 30, \\ 30-059 Kraków, Poland; micek_pt@agh.edu.pl \\ * Correspondence: dariusz.grzybek@agh.edu.pl; Tel.: +48-126-173-080
}

check for updates

Citation: Micek, P.; Grzybek, D. Experimental Analysis of the Arrays of Macro Fiber Composite Patches for Rotational Piezoelectric Energy Harvesting from a Shaft. Energies 2021, 14, 4815. https://doi.org/ 10.3390/en14164815

Academic Editor: Andrea Mariscotti

Received: 5 July 2021

Accepted: 4 August 2021

Published: 7 August 2021

Publisher's Note: MDPI stays neutral with regard to jurisdictional claims in published maps and institutional affiliations.

Copyright: (c) 2021 by the authors. Licensee MDPI, Basel, Switzerland. This article is an open access article distributed under the terms and conditions of the Creative Commons Attribution (CC BY) license (https:// creativecommons.org/licenses/by/ $4.0 /)$.

\begin{abstract}
Four arrays of three MFC patches, glued onto a rotating shaft, were compared in laboratory research. The first array was based on a delta circuit and equipped with one three-phase rectifier; the second array was based on a star circuit and equipped with one three-phase rectifier; the third array was based on parallel connection and equipped with three full-bridge rectifiers; and the fourth array was based on a series connection and equipped with three full-bridge rectifiers. The array based on a delta circuit generated the highest value of maximal electric power in comparison to the rest of arrays. It was experimentally observed that the arrays based on delta or star circuits of MFC patches and equipped with one three-phase rectifier generated a higher value of maximal power than arrays based on the connections of three full-bridge rectifiers, connected in parallel or in series. The array based on parallel connection generated the highest maximal value of current in comparison to rest of arrays for low values of load resistance (from $10 \mathrm{k} \Omega$ to $40 \mathrm{k} \Omega$ depending on the experiment). For higher values of load resistance arrays based on delta circuits and star circuits generated higher values of current than the array based on parallel connection.
\end{abstract}

Keywords: piezoelectric energy harvesting; rotational piezoelectric energy harvesting; piezoelectric harvester; Macro Fiber Composite; machine shaft; three-phase rectifier; full-bridge rectifier

\section{Introduction}

Piezoelectric energy harvesting is a process in which piezoelectric materials convert mechanical energy into electrical energy. Special devices which are called energy harvesters are used to energy conversion. Rotating elements of mechanical devices e.g., machine shafts, fans, car wheels are some of the sources of mechanical energy which can be harvested. Wang et al. [1] proposed the classification of piezoelectric harvesting systems for rotating applications based on four groups of excitation conditions: inertial excitation, contact excitation, magnetic coupling and hybrid. Energy harvesters for rotational motion can be divided into two categories: devices based on a single element containing piezoelectric material and devices based on an array of elements containing piezoelectric material. The first category includes various harvester structures in which one patch of piezoelectric material is deformed by a mechanical structure, most often a cantilever beam. A cantilever beam is made from piezoelectric material, e.g., lead zirconate titanate (PZT), which is glued on to the carrying substrate [2-6]. Energy harvesting can be also realized by the use of a patch of piezoelectric material, which is directly glued onto the rotating element, e.g., a Macro Fiber Composite (MFC) glued onto a shaft [7]. The second category includes harvester structures based on an array of elements containing piezoelectric material, also most often a cantilever beam, e.g., two cantilevers [8], two clamped-clamped beams [9,10], three cantilevers [11-13], four cantilevers [14-16], six cantilevers [17], eight cantilevers [18,19], nine cantilevers [20] or twelve cantilevers [21,22]. The greater number of elements with piezoelectric material, the larger amount of electric energy can be harvested. However, 
greater numbers of such elements causes more complexity across the whole of the energy harvesting system. The choice of this number is therefore a compromise between the amount of harvested energy and the complexity of the harvesting system of this energy.

A standard energy harvesting (SEH) interface circuit composed of a full-bridge rectifier is commonly used in rotational piezoelectric energy harvesting, based on a single element containing piezoelectric material [2-4]. SEH circuits have been developed by scientists, e.g., Yan et al. [5] proposed the addition of a zener diode to protect the front-end circuit. A Synchronized Switch Harvesting on Inductor (SSHI) circuit is also applied in harvesting from a rotating application. The basic structure of an SSHI circuit has been improved by researchers, e.g., Cheng et al. [6] proposed the development of SSHI for a bistable rotary harvesting system by adding a self-powered voltage control circuit. Circuits based on SEH or on SSHI are also applied in rotary energy harvesters containing more than one piezoelectric element. However, the electrical connection of piezoelectric elements is a distinctly scientific problem, because the rotational harvesting system, with its multiple piezoelectric elements, generates several various waveforms of electrical response. Several piezoelectric elements, which are not equipped by a full-bridge rectifier, may be parallel or series, connected only when they generate the same or opposite voltage [14]. Piezoelectric elements, each of which is equipped by a full-bridge rectifier, may be parallel $[8,9,15]$ or series [9], connected independently from generated waveforms of voltage. It can be noticed that the number of used full-bridge rectifiers is equal to the number of piezoelectric elements. Each rectifier causes energy losses in its diodes, a basic disadvantage of this connection. Kurt et al. [12] and Bouzelata et al. [13] proposed the application of one three-phase rectifier circuit in energy harvesters containing three piezoelectric beams, which generated three various waveforms of voltage. Piezoelectric beams in the cited works [12,13] were connected by the use of a star circuit. However, electrical responses for the described harvester with one three-phase rectifier did not compare with the responses of harvesters with three standard interface circuits (with full-bridge rectifiers).

This paper presents an experimental analysis of the arrays of three MFC patches, which were used for energy harvesting from a rotating shaft. MFC patches were directly glued onto the surface of the rotating shaft. This way of energy harvesting was classified to contact of the excitation group by Wang et al. [1]. Three MFC patches were chosen because a three-phase rectifier was tested in laboratory experiments. MFC patches were connected by the use of a star circuit (similar to [12,13]) and a delta circuit, which is a second way to connect three electrical sources with a three-phase rectifier. The star and delta circuits were compared with three full-bridge rectifiers connected in parallel and in series, a practice which is often reported in the literature, e.g., $[8,9,15]$. In contrast to what is presented in the results of the literature, MFC patches were connected by the use of a delta circuit and electrical responses for energy harvesters, with the delta circuit of MFC patches compared with both the electrical responses of energy harvesters with star circuits, and with the electrical responses of energy harvesters with three full-bridge rectifiers connected in parallel and in series.

\section{Laboratory Setup}

The laboratory stand, whose schema is presented in Figure 1, consisted of the rotating shaft, a system of rotational motion and force generation, a piezoelectric energy harvesting system and a measurement system. The rotating shaft was made from steel and had an annulus cross-section. The shaft was fixed in two bearings. Geometric and material properties of the rotating shaft are listed in Table 1.

The system of rotational motion and force generation consisted of a belt transmission with a timing belt, an asynchronous motor with a frequency inverter and a screw gear. A similar system was presented in [23]. The rotational speed of the motor shaft was changed by the use of the frequency inverter. An application of the belt transmission was that it allowed rotation changes in a range from 1 to 20 rotations per second, to be obtained. Shaft bearings were mounted on a moving plate, which was installed on a motionless stand body 
by the use of two linear bearings. This structure allowed for a displacement of the moving plate relative to the motionless stand body by the use of a screw gear. Displacements of the moving plate changed the tension of timing belt and the force acting on the shaft, the latter of which was measured by the use of a force sensor.

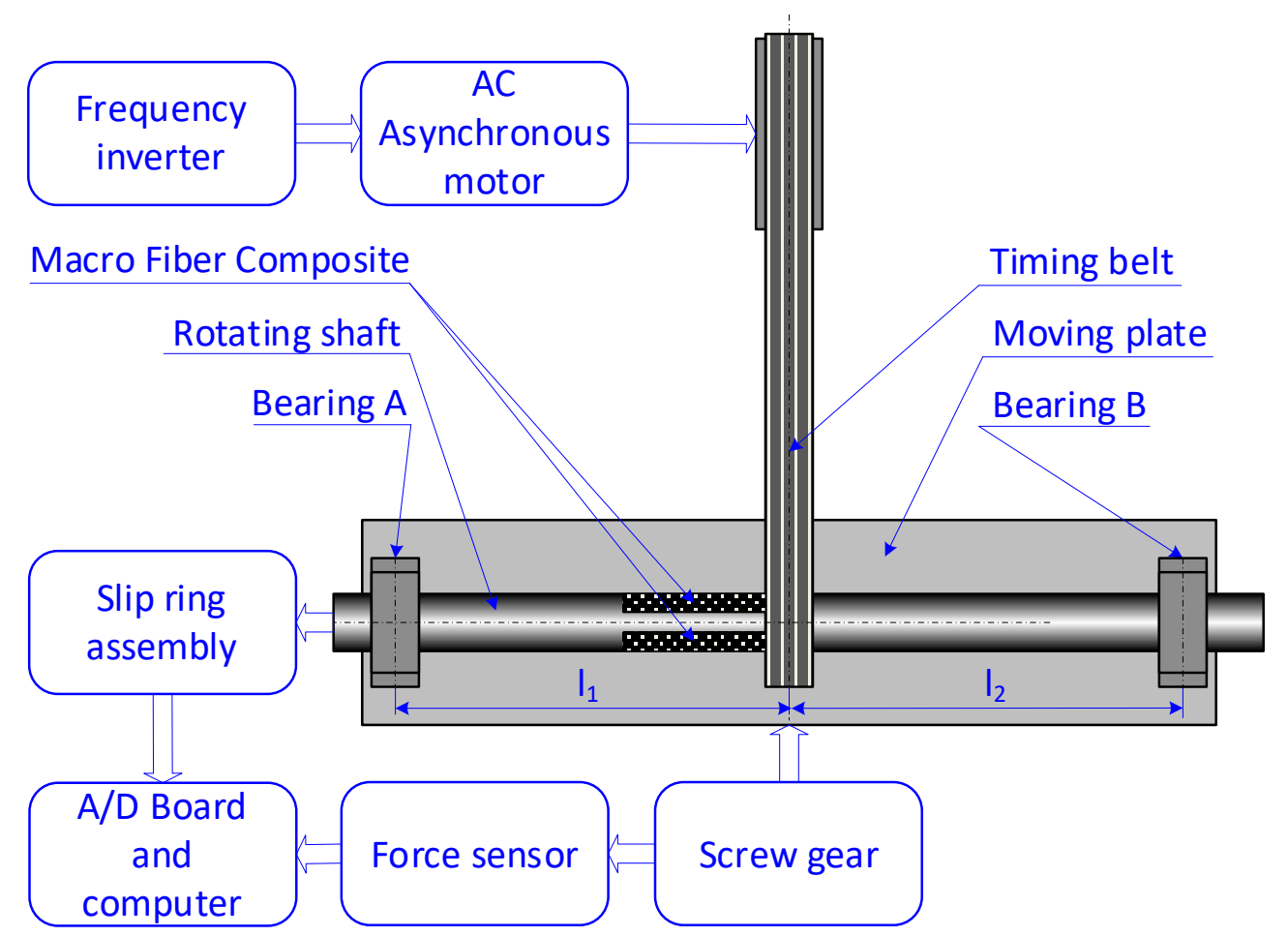

Figure 1. Schema of laboratory stand.

Table 1. Geometric and material properties of shaft.

\begin{tabular}{cccc}
\hline Parameter & Symbol & Unit & Value \\
\hline External diameter of shaft & Dso & $\mathrm{mm}$ & 40 \\
Internal diameter of shaft & Dsi & $\mathrm{mm}$ & 36 \\
Young's modulus of steel & Ys & $\mathrm{Pa}$ & $205 \times 10^{9}$ \\
Distance between bearing A and center of shaft & $1_{1}$ & $\mathrm{~mm}$ & 310 \\
Distance between bearing B and center of shaft & $1_{2}$ & $\mathrm{~mm}$ & 310 \\
\hline
\end{tabular}

The piezoelectric energy harvesting system contained three patches of P2 type Macro Fiber Composite (MFC), manufactured by Smart Material Corporation, and one three-phase rectifier or three full-bridge rectifiers. MFC patches were directly glued onto the shaft surface. The displacement of MFC patches on the shaft surface is presented in Figure 2.

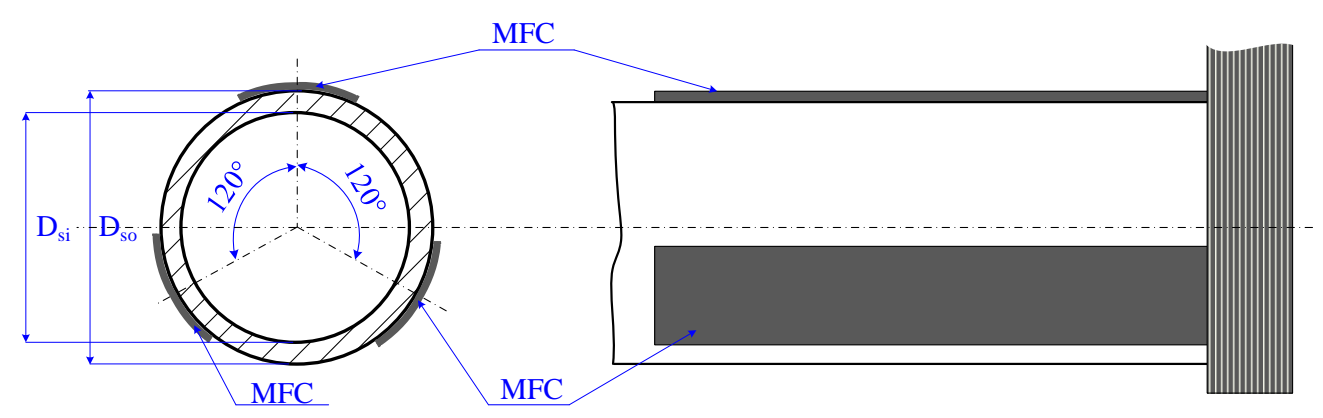

Figure 2. Displacement of MFC patches on shaft surface.

The geometric and material properties of MFC patches are listed in Table 2. 
Table 2. Geometric and material properties of MFC patches [24-26].

\begin{tabular}{cccc}
\hline Parameter & Symbol & Unit & Value \\
\hline Length of piezoelectric area inside MFC patch & $\mathrm{l}_{\mathrm{p}}$ & $\mathrm{mm}$ & 85 \\
Overall length of MFC patch & $\mathrm{l}_{\mathrm{MFC}}$ & $\mathrm{mm}$ & 100 \\
Width of piezoelectric area in MFC patch & $\mathrm{w}_{\mathrm{p}}$ & $\mathrm{mm}$ & 14 \\
Thickness of MFC patch & $\mathrm{t}_{\mathrm{MFC}}$ & $\mathrm{mm}$ & 0.3 \\
Thickness of piezoelectric fiber inside MFC patch & $\mathrm{t}_{\mathrm{pf}}$ & $\mathrm{mm}$ & 0.18 \\
Piezoelectric constant of piezoelectric fibers & $\mathrm{d}_{31}$ & $\mathrm{C} / \mathrm{N}$ & $-185 \times 10^{-12}$ \\
Relative permittivity of piezoelectric fibers & $\varepsilon_{33}^{T} / \varepsilon_{0}$ & - & 1850 \\
Young modulus of piezoelectric fibers & $\mathrm{Y}_{\mathrm{p}}$ & $\mathrm{Pa}$ & $54.05 \times 10^{9}$ \\
\hline
\end{tabular}

Two types of MFC are manufactured by the Smart Material Corporation: P1 and $\mathrm{P} 2$. In the P1 type, polarization direction is along the length of the piezoelectric fibers; in the P2 type, polarization direction is through the thickness of the piezoelectric fibers. P2 configuration was selected because it had a lower electrical impedance than the P1 type due to a higher device capacitance [27] and enabled higher charge generation at the same strain level compared with the P1 type MFC [28].

The measurement system consisted of a slip ring assembly, A/D board and force sensor. DaQBoard 2000 about resolution: 16 bit, produced by IOTech, was used as the A/D board. The measurement of current was realized by the use of an ADAM-3016 amplifier, produced by Adwantech. The ADAM-3016 amplifier had an input signal of $\pm 10 \mathrm{mV}$ and an output signal of $\pm 10 \mathrm{~V}$. A resistor of $10 \mathrm{Ohm}$ was used for the conversion of the current, generated by energy harvesting systems, to the voltage signal which was adapted to the ADAM-3016 amplifier. The L6E sensor, produced by the Zemic company, was used for the measurement of the force which acted on shaft in the place where the grooved pulley was located. Conduits between MFC patches and A/D Board were led through the inside of the rotating shaft and by the slip ring assembly, produced by Hottinger Baldwin Messtechnik HBM. The view of the laboratory stand is presented in Figure 3.

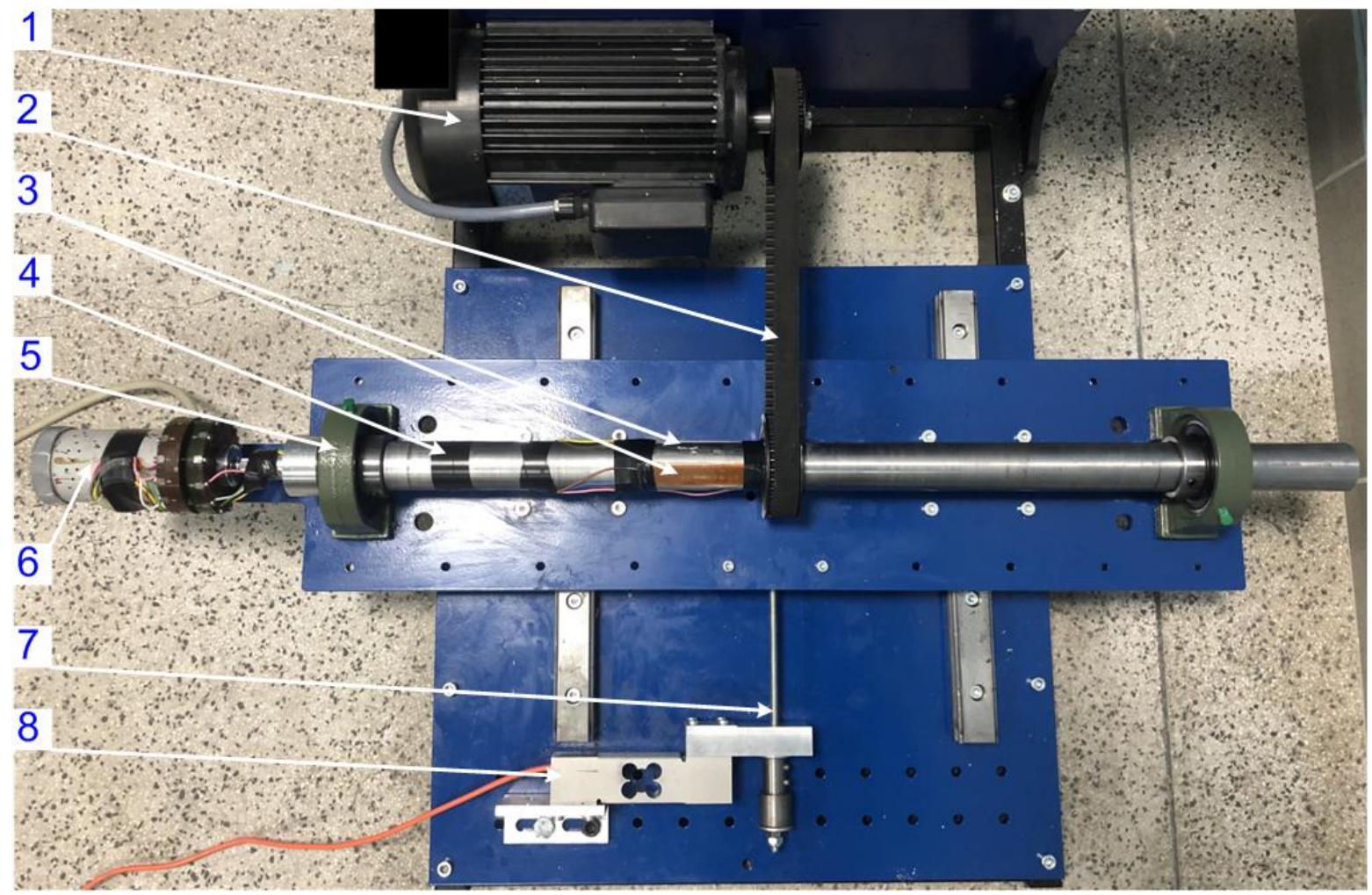

Figure 3. View of laboratory stand: 1-asynchronous motor, 2-belt transmission, 3-patches of Macro Fiber Composite, 4-rotating shaft, 5-bearing, 6-slip ring, 7—screw gear, 8-force sensor. 


\section{Results}

\subsection{Array of Macro Fiber Composite Patches}

Three MFC patches were connected in laboratory experiments using the following arrays:

- $\quad$ MFC patches were connected with each other using a delta circuit. An MFC delta circuit was equipped with a three-phase rectifier (Figure 4a);

- $\quad$ MFC patches were connected with each other using a star circuit. An MFC star circuit was equipped with a three-phase rectifier (Figure $4 b$ );

- $\quad$ MFC patches were not connected with each other. Each MFC patch was equipped with a full-bridge rectifier. Subsystems consisting of MFC and rectifier were parallel connected (Figure 4c);

- $\quad$ MFC patches were not connected with each other. Each MFC patch was equipped with a full-bridge rectifier. Subsystems consisting of MFC and rectifier were series connected (Figure 4d).

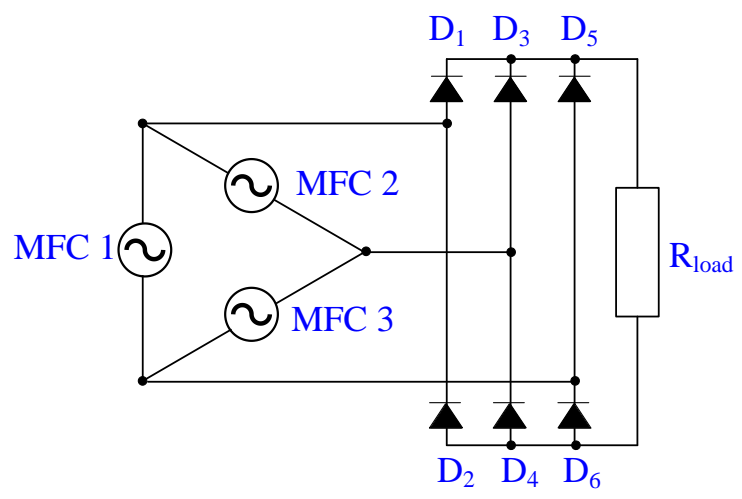

(a)

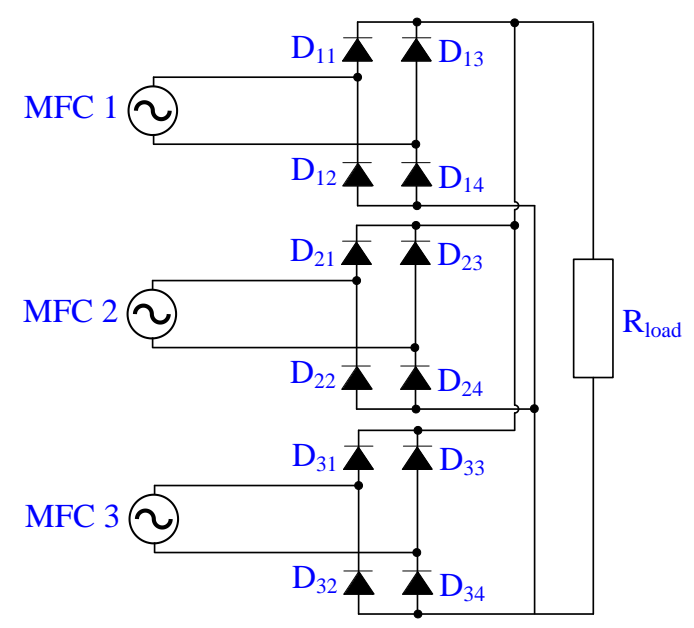

(c)

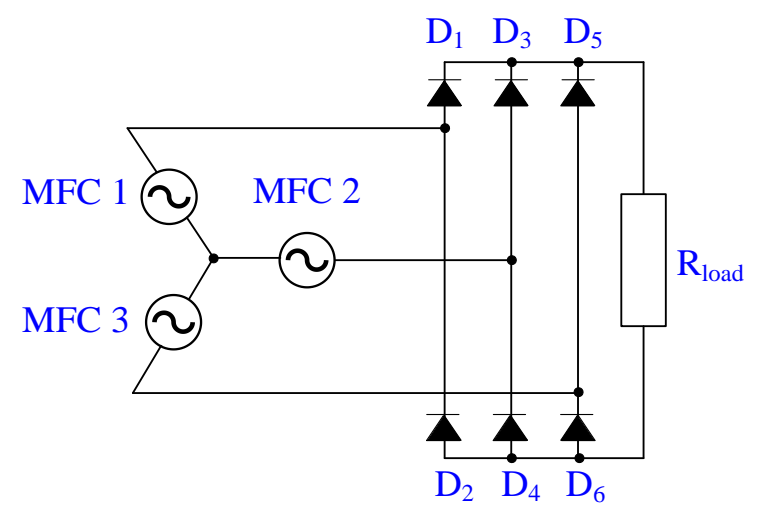

(b)

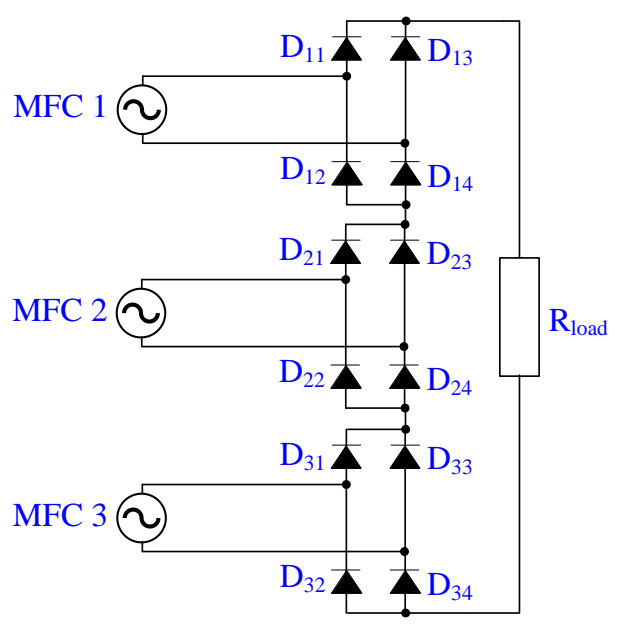

(d)

Figure 4. Arrays of three MFC patches: (a) delta circuit; (b) star circuit; (c) parallel connection; (d) series connection.

\subsection{Conditions of Laboratory Experiments}

Laboratory research consisted of nine experiments. Four arrays of three MFC patches (Figure 4) were tested in each of these nine experiments. The results of the experiments differed in the values of force acting on the shaft and the values of the rotational speed of shaft. Table 3 presents conditions of each of the experiments. 
Table 3. Conditions of laboratory experiments.

\begin{tabular}{|c|c|c|c|c|c|c|c|c|c|c|c|}
\hline & & & \multicolumn{9}{|c|}{ Number of Experiment } \\
\hline & & & 1 & 2 & 3 & 4 & 5 & 6 & 7 & 8 & 9 \\
\hline Parameter & Symbol & Unit & \multicolumn{9}{|c|}{ Value of Parameter in Experiment } \\
\hline Force acting on shaft & $\mathrm{F}_{\mathrm{b}}$ & $\mathrm{N}$ & 200 & 200 & 200 & 400 & 400 & 400 & 600 & 600 & 600 \\
\hline Rotational speed of shaft & $\mathrm{n}$ & rps & 10 & 15 & 20 & 10 & 15 & 20 & 10 & 15 & 20 \\
\hline
\end{tabular}

Values of load resistance $R_{\text {load }}$ changed from $10 \mathrm{k} \Omega$ to $487 \mathrm{k} \Omega$ in each of the experiments.

\subsection{Current Generated by MFC Arrays}

Figure 5 presents results from the first three experiments in which the current generated by MFC arrays was measured. The force acting on the shaft was equal to $200 \mathrm{~N}$.

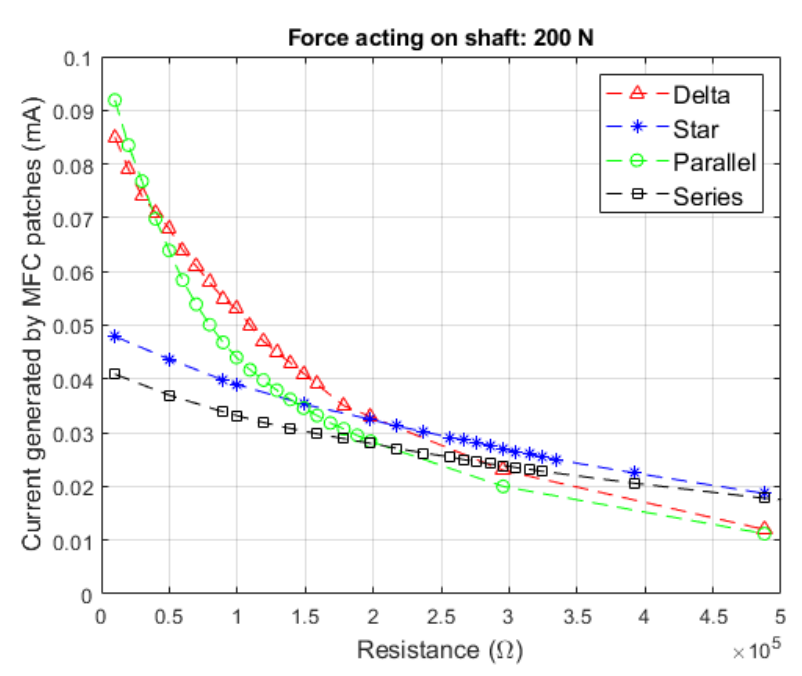

(a)

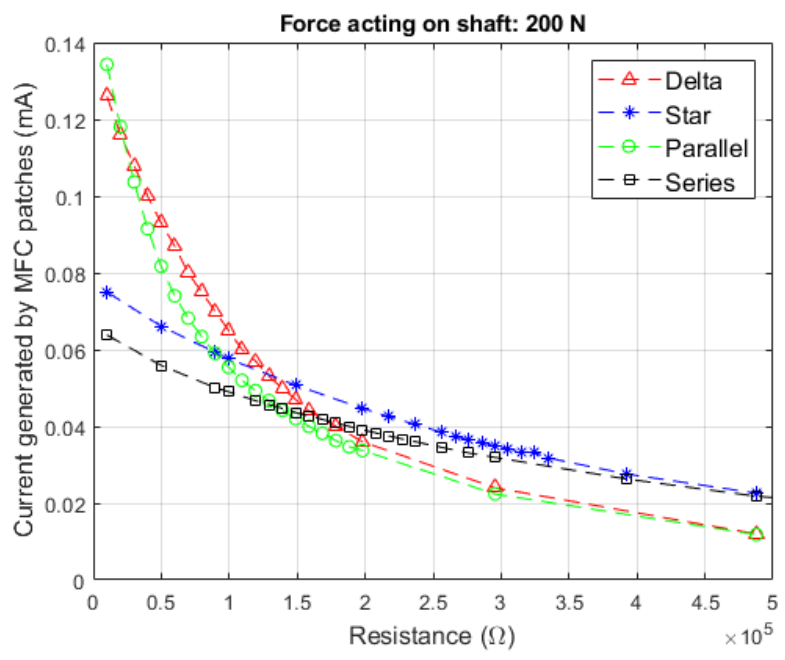

(b)

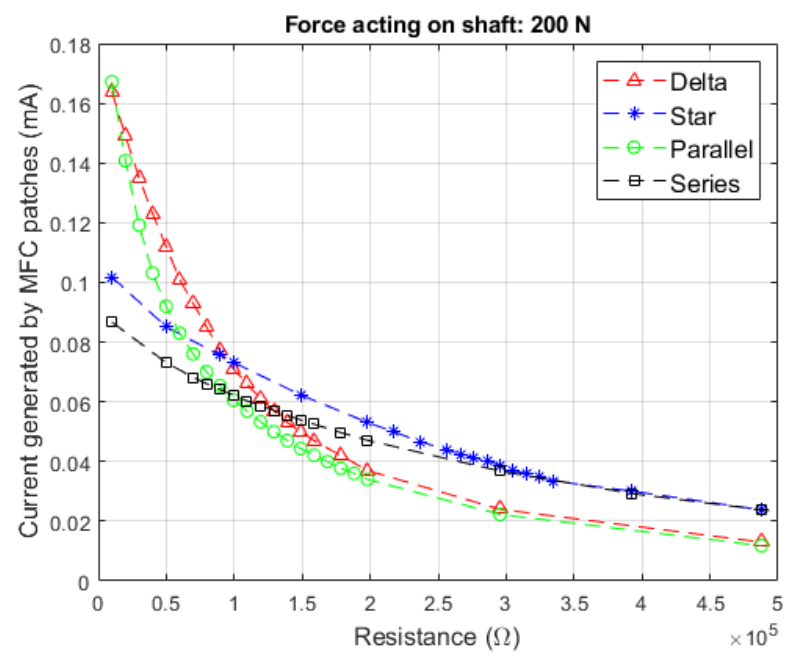

(c)

Figure 5. Current generated for a force equal to $200 \mathrm{~N}$ : (a) rotational speed equal to $10 \mathrm{rps}$; (b) rotational speed equal to $15 \mathrm{rps}$; and (c) rotational speed equal to $20 \mathrm{rps}$.

Figure 6 presents three experiments in which the force acting on the shaft was equal to $400 \mathrm{~N}$. 


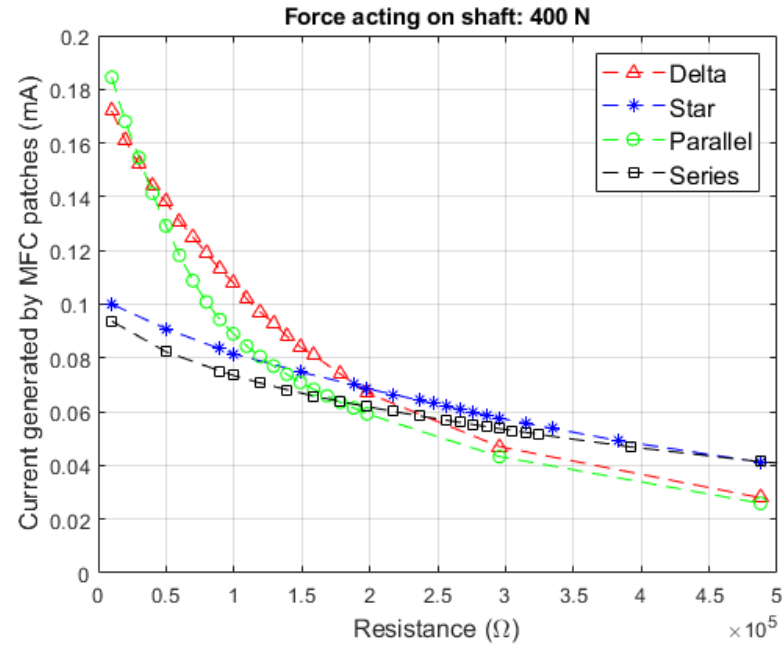

(a)

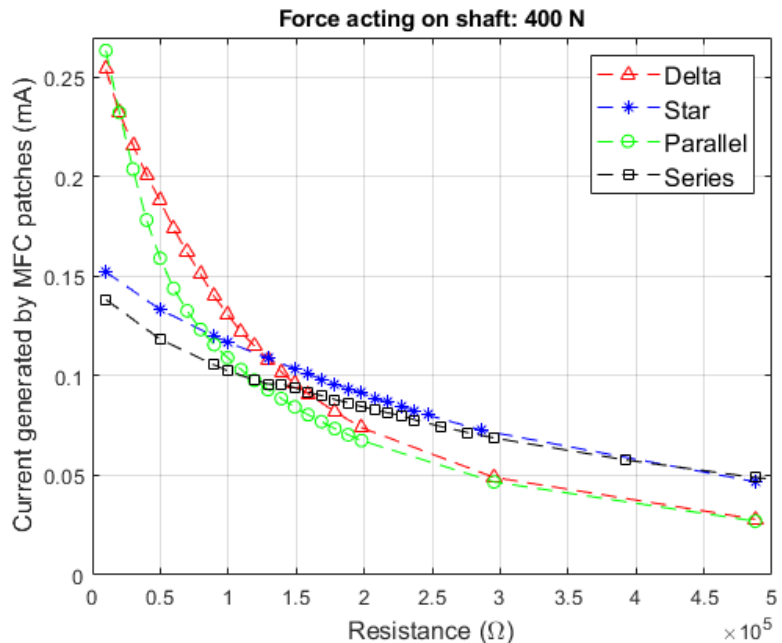

(b)

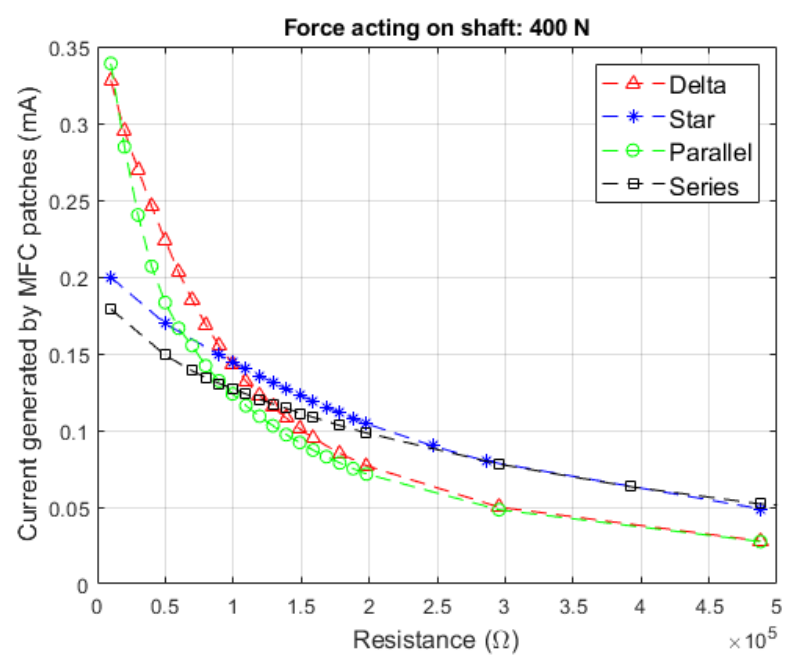

(c)

Figure 6. Electrical power generated for a force equal to $400 \mathrm{~N}$ : (a) rotational speed equal to $10 \mathrm{rps}$; (b) rotational speed equal to $15 \mathrm{rps}$; and (c) rotational speed equal to $20 \mathrm{rps}$. $600 \mathrm{~N}$.

Figure 7 presents three experiments in which the force acting on shaft was equal to

\subsection{Electric Power Generated by MFC Arrays}

On the basis of measured current and load resistance, the power generated by the arrays of MFC patches was calculated on the basis of a known formula:

$$
P_{p}(t)=i_{p}(t)^{2} R_{l o a d}
$$

where $i_{p}$ is the current generated by the array of the MFC patches and $R_{\text {load }}$ is load resistance.

Figure 8 presents the courses of electrical power for the first three experiments in which the force acting on the shaft was equal to $200 \mathrm{~N}$. 


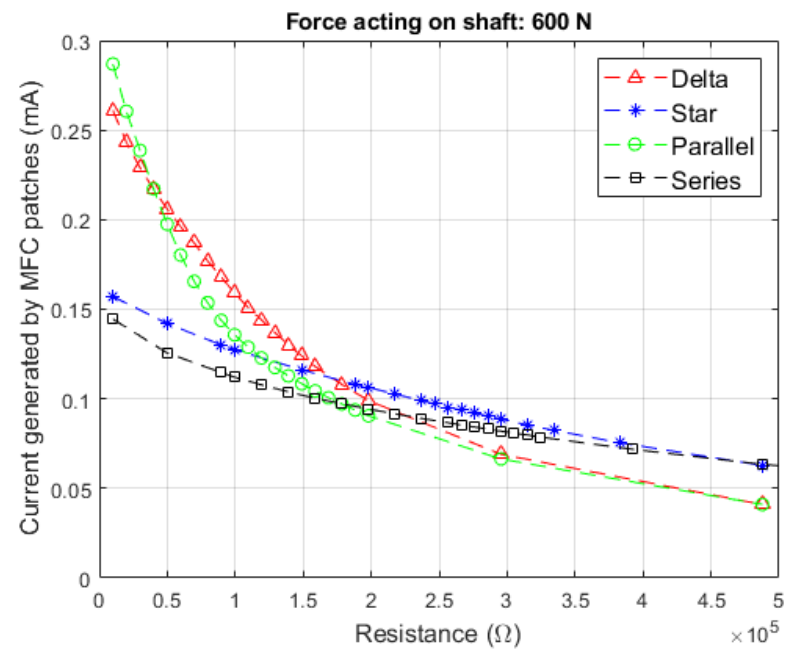

(a)

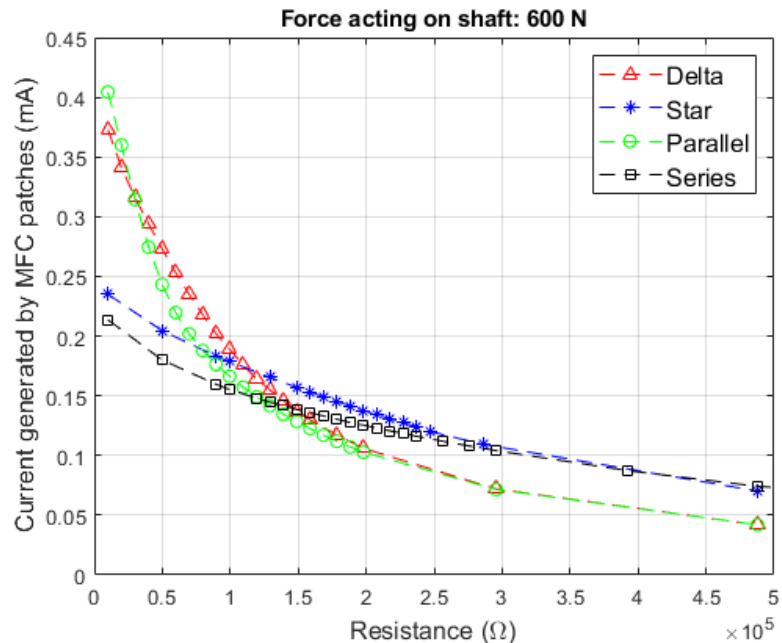

(b)

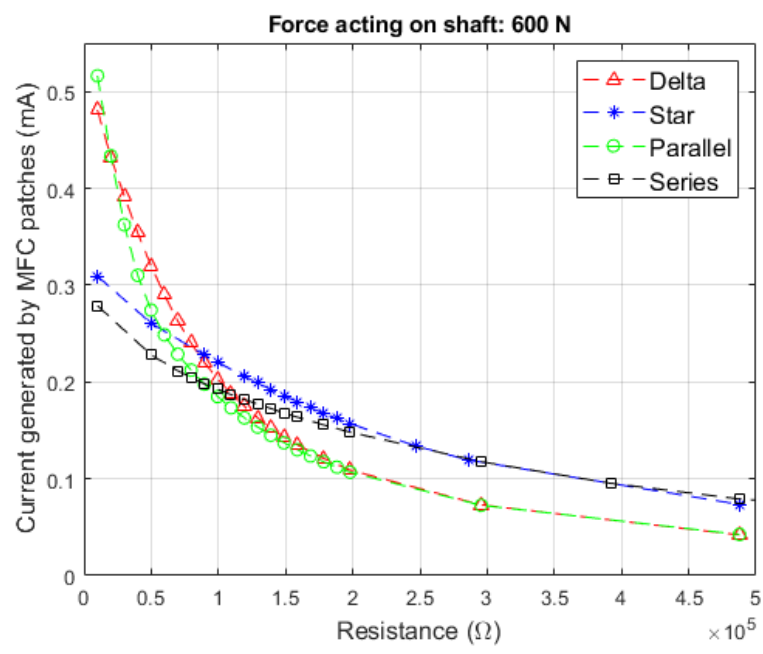

(c)

Figure 7. Electrical power generated for a force equal to $600 \mathrm{~N}$ : (a) rotational speed equal to $10 \mathrm{rps}$; (b) rotational speed equal to $15 \mathrm{rps}$; and (c) rotational speed equal to $20 \mathrm{rps}$. 


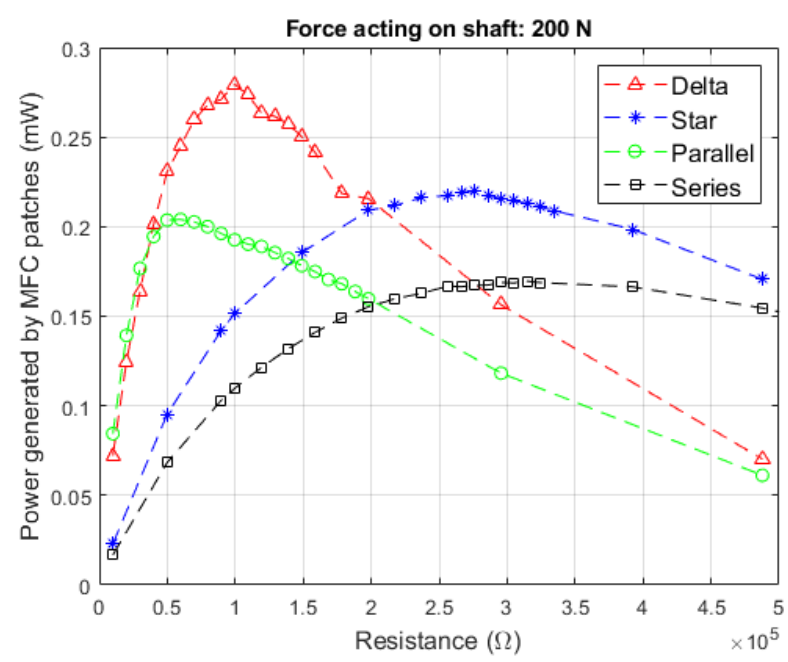

(a)

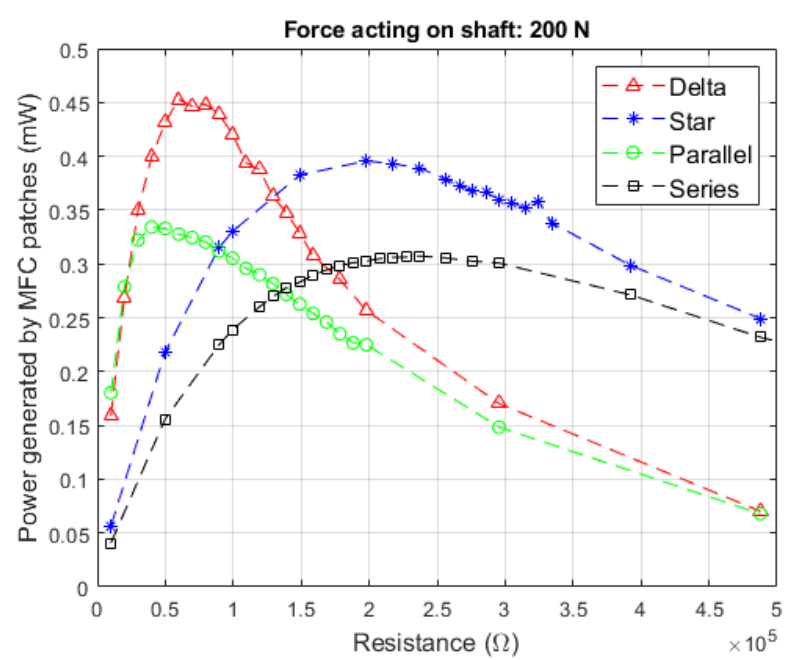

(b)

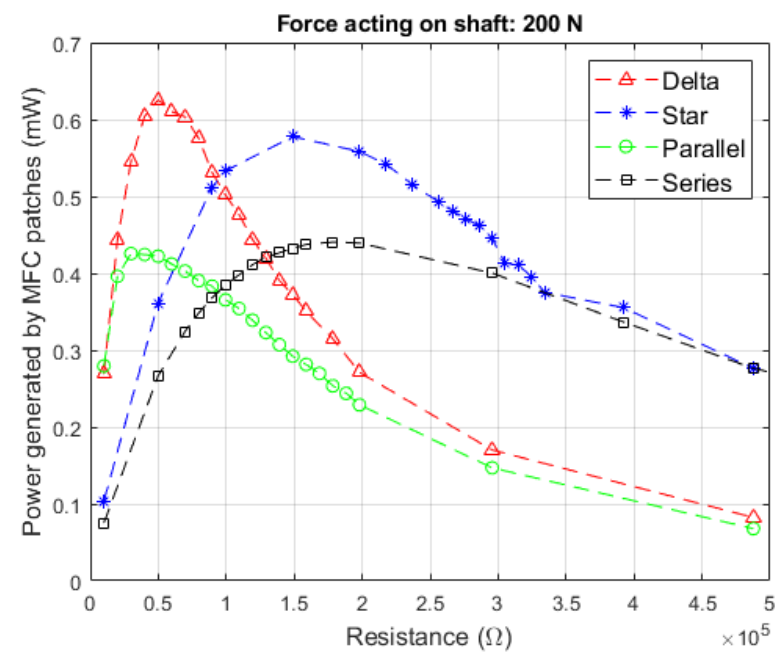

(c)

Figure 8. Electrical power generated for a force equal to $200 \mathrm{~N}$ : (a) rotational speed equal to $10 \mathrm{rps}$; (b) rotational speed equal to $15 \mathrm{rps}$; and (c) rotational speed equal to $20 \mathrm{rps}$.

Figure 9 presents three experiments in which force acting on the shaft was equal to $400 \mathrm{~N}$. 


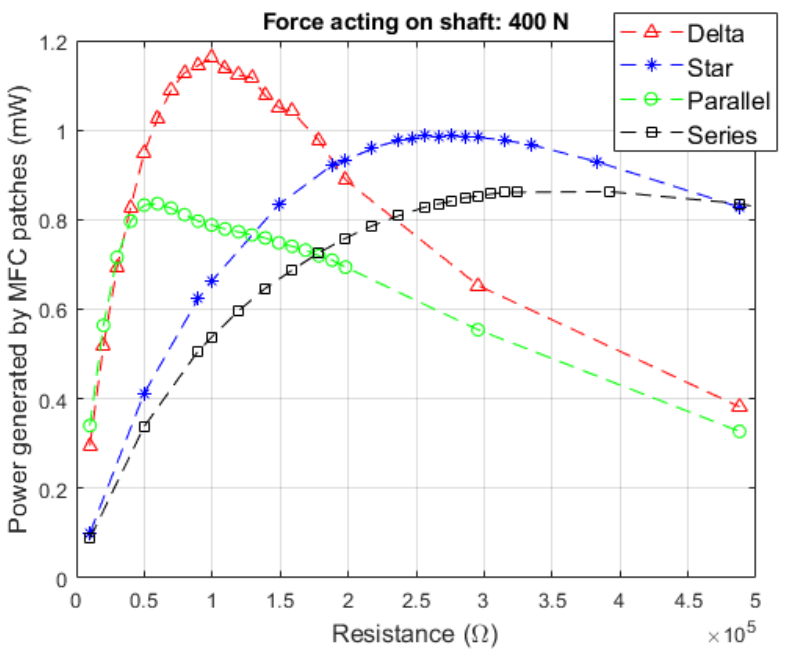

(a)

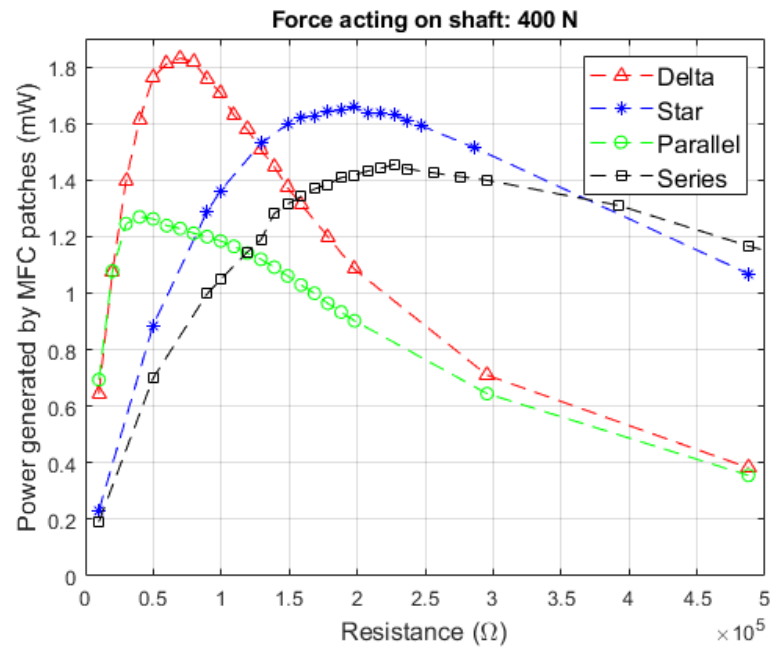

(b)

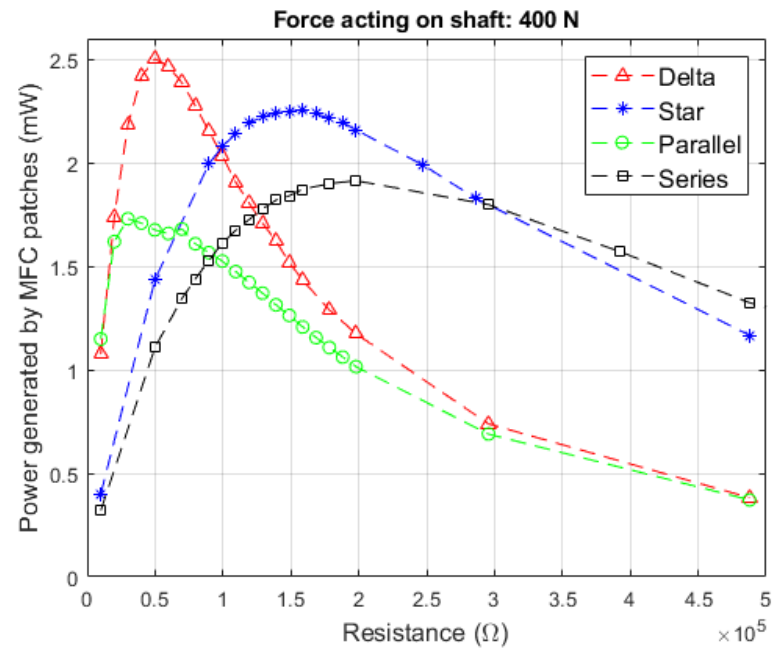

(c)

Figure 9. Electrical power generated for a force equal to $400 \mathrm{~N}$ : (a) rotational speed equal to $10 \mathrm{rps}$; (b) rotational speed equal to $15 \mathrm{rps}$; and (c) rotational speed equal to $20 \mathrm{rps}$.

Figure 10 presents three experiments in which the force acting on the shaft was equal to $600 \mathrm{~N}$. 


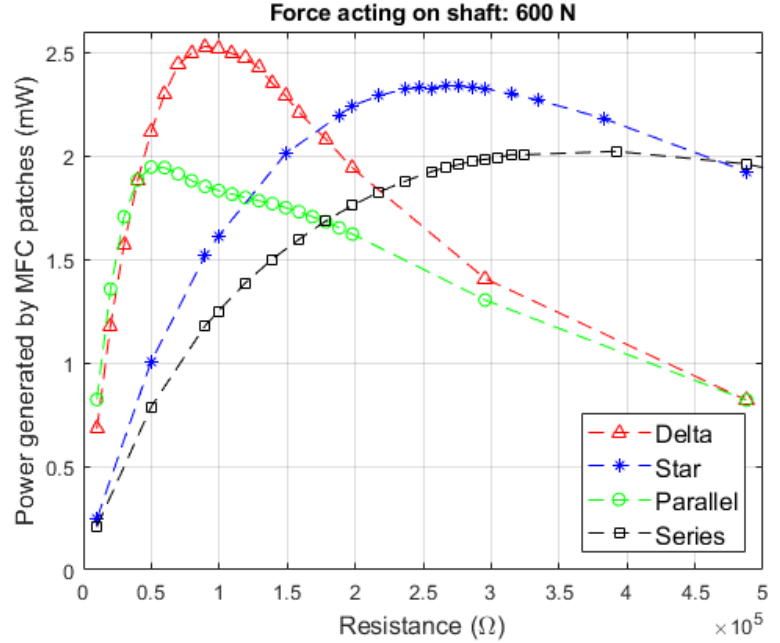

(a)

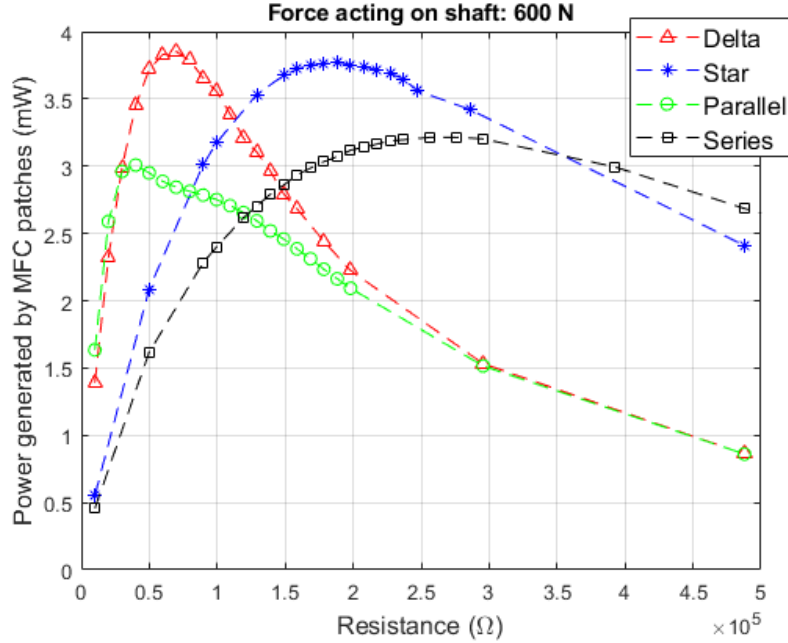

(b)

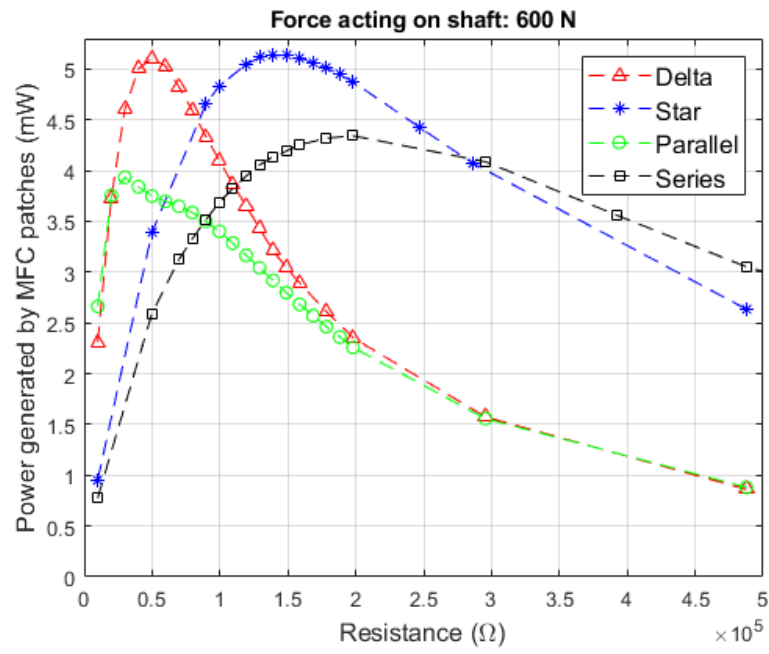

(c)

Figure 10. Electrical power generated for a force equal to $600 \mathrm{~N}$ : (a) rotational speed equal to $10 \mathrm{rps}$; (b) rotational speed equal to $15 \mathrm{rps}$; and (c) rotational speed equal to $20 \mathrm{rps}$.

\section{Discussion}

The maximal value of electric power was the highest for the array based on a delta circuit in eight out of nine experiments (Table 4).

Table 4. Maximal value of generated electric power.

\begin{tabular}{cccccccccc}
\hline & \multicolumn{8}{c}{ Number of Experiment } \\
\cline { 2 - 9 } Array & $\mathbf{1}$ & $\mathbf{2}$ & $\mathbf{3}$ & $\mathbf{4}$ & $\mathbf{5}$ & $\mathbf{6}$ & $\mathbf{7}$ & $\mathbf{8}$ & $\mathbf{9}$ \\
\cline { 2 - 9 } & \multicolumn{8}{c}{ Maximal Values of Electric Power (mW) } \\
\hline Delta circuit & 0.2795 & 0.4527 & 0.6256 & 1.1605 & 1.8306 & 2.5025 & 2.5287 & 3.8522 & 5.1072 \\
Star circuit & 0.2195 & 0.3956 & 0.5778 & 0.9874 & 1.6578 & 2.2553 & 2.3389 & 3.7737 & 5.1396 \\
Parallel connection & 0.2040 & 0.3342 & 0.4256 & 0.8357 & 1.2690 & 1.7297 & 1.9454 & 3.0079 & 3.9341 \\
Series connection & 0.1695 & 0.3073 & 0.4406 & 0.8625 & 1.4552 & 1.9134 & 2.0221 & 3.2148 & 4.3432 \\
\hline
\end{tabular}

It was experimentally observed that the arrays based on one three-phase rectifier (for both delta and star circuits) generated higher values of maximal power than arrays 
based on the connection of three full-bridge rectifiers (parallel and series connection). The comparison of maximal electrical power is presented in Figure 11.

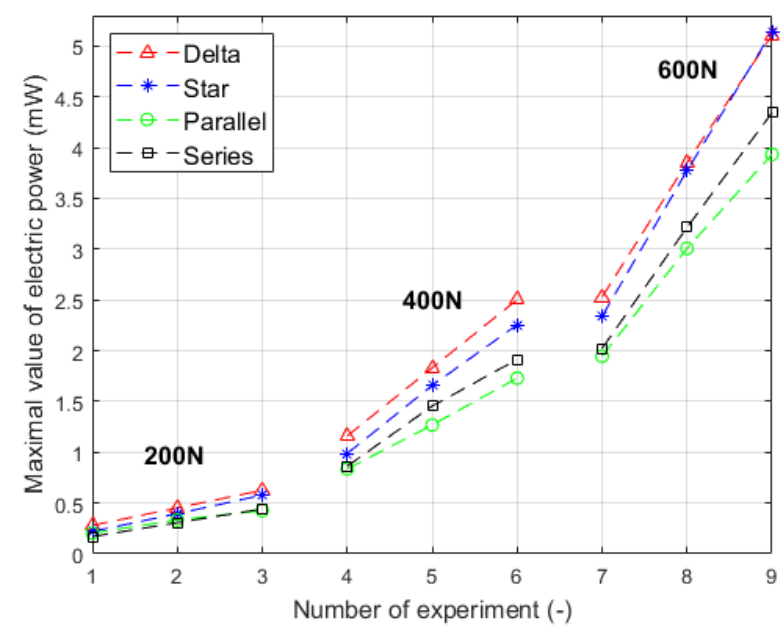

Figure 11. Comparison of maximal values of electrical power for MFC arrays.

Values of optimal load resistance, for which maximal value of electric power was obtained, are presented in Table 5.

Table 5. Values of optimal load resistance.

\begin{tabular}{cccccccccc}
\hline & \multicolumn{8}{c}{ Number of Experiment } \\
\cline { 2 - 10 } Array & $\mathbf{1}$ & $\mathbf{2}$ & $\mathbf{3}$ & $\mathbf{4}$ & $\mathbf{5}$ & $\mathbf{6}$ & $\mathbf{7}$ & $\mathbf{8}$ & $\mathbf{9}$ \\
\cline { 2 - 10 } & \multicolumn{8}{c}{ Optimal Load Resistance (k $\mathbf{\Omega})$} \\
Delta circuit & 99.5 & 59.8 & 49.8 & 99.5 & 69.7 & 49.8 & 89.5 & 69.7 & 49.8 \\
Star circuit & 276.1 & 198.0 & 148.8 & 276.1 & 198.0 & 158.7 & 266.4 & 188.2 & 148.8 \\
Parallel connection & 59.8 & 39.9 & 29.9 & 59.8 & 39.9 & 29.9 & 49.8 & 39.9 & 29.9 \\
Series connection & 314.9 & 237.1 & 178.3 & 392.1 & 227.3 & 198.0 & 392.1 & 276.1 & 198.0 \\
\hline
\end{tabular}

Notably, the optimal load resistance for the array based on a delta circuit is closer to the optimal load resistance for the array based on parallel connection than it is for series connection. Hence, the array based on a delta circuit should be compared with the array based on a parallel connection in a field of maximum power generation. On the other hand, the array based on a star circuit should be compared with the array based on series connection. It was experimentally observed that the array based on a delta circuit generated higher values of maximal electric power than the array based on a parallel connection in each of the experiments. The array based on a star circuit generated higher values of maximal electric power than the array based on a series connection in each of the experiments.

The optimal load resistance was around three times smaller for the array based on a delta circuit in comparison to the array based on a star circuit. This resulted from a known principle according to which a star circuit generates a greater value of voltage and smaller values of current in comparison to a delta circuit. Taking into account that the value of voltage generated by piezoelectric material (MFC) was decreased by a subtrahend, proportional to a change (derivative) of generated voltage [7], greater voltage losses occurred in the array based on a star circuit than the array based on a delta circuit for the same values of force acting on the shaft and the rotational speed of shaft. It can be noted that an increase in the values of force and rotational speed caused a decrease in the optimal load resistance and optimal voltage. This meant that voltage losses decreased in the array based on a star circuit when the values of force and rotational speed increased. Hence, the power generated by the arrays based on delta circuits was almost the same in all nine 
experiments. The delta circuits and star circuits had a higher maximum power in both parallel connection and series connection, the result of smaller voltage losses on diodes in the rectifiers of the delta or star circuits in comparison to parallel or series connections. Smaller voltage losses resulted from a lower number of used diodes in delta or star circuits (six diodes) in comparison to parallel and series connections (12 diodes).

For the largest values of load resistance, power generated by the array based on a delta circuit and by the array based on a star circuit was almost the same in each of the experiments. It resulted from a phenomenon according to which the value of voltage generated by piezoelectric material (MFC) is decreased by a subtrahend which is proportional to a change (derivative) in generated voltage [7]. Hence, the voltage generated by arrays (delta and star) tended to be the same value despite an increase in load resistance. For the same reason, a similar value of power occurred in both parallel and series connections for the largest values of load resistance. A series connection of three MFC patches was better than parallel connection for producing a maximum power value in seven out of the nine experiments (Table 4). This observation was similar to the observation of Song at al. [29] that the series connection of two MFC patches in bending bimorph is better than its equivalent parallel connection, for producing the maximum power. However, it was experimentally observed that the array based on a delta circuit was better for producing the maximum power than the array based on a star circuit. Hence, the relation between the array based on a delta circuit and the array based on a star circuit is not similar to the relation between the array based on parallel connection and the array based on series connection, in a field of maximum power generation.

In each of the nine experiments the array based on a delta circuit was better for producing the maximum current than the array based on a star circuit (Table 6).

Table 6. Maximal values of generated current.

\begin{tabular}{cccccccccc}
\hline & \multicolumn{8}{c}{ Number of Experiment } \\
\cline { 2 - 10 } Array & $\mathbf{1}$ & $\mathbf{2}$ & $\mathbf{3}$ & $\mathbf{4}$ & $\mathbf{5}$ & $\mathbf{6}$ & $\mathbf{7}$ & $\mathbf{8}$ & $\mathbf{9}$ \\
\cline { 2 - 9 } & \multicolumn{8}{c}{ Maximal Values of Current (mA) } \\
Delta circuit & 0.085 & 0.126 & 0.164 & 0.172 & 0.254 & 0.328 & 0.261 & 0.373 & 0.481 \\
Star circuit & 0.047 & 0.075 & 0.103 & 0.100 & 0.152 & 0.199 & 0.157 & 0.235 & 0.309 \\
Parallel connection & 0.091 & 0.134 & 0.167 & 0.184 & 0.263 & 0.339 & 0.286 & 0.404 & 0.516 \\
Series connection & 0.040 & 0.063 & 0.086 & 0.093 & 0.138 & 0.179 & 0.144 & 0.213 & 0.278 \\
\hline
\end{tabular}

The array based on the parallel connection of three MFC patches generated higher values of maximum current than the array based on its series connection equivalent. This observation was similar to the observations of other researchers $[29,30]$ that the parallel connection of two MFC patches in bending bimorph generated higher maximum current than its series connection. Hence, the relation between the array based on a delta circuit and the array based on a star circuit was similar to the relation between the array based on parallel connection and the array based on series connection in a field of maximum current generation. It was experimentally observed that the arrays based on parallel connection generated the highest values of maximal current in comparison to the rest of the MFC arrays (Figure 12).

However, the array based on parallel connection generated higher values of current in comparison to the rest of arrays, only for low values of load resistance; from $10 \mathrm{k} \Omega$ to $40 \mathrm{k} \Omega$, depending on the experiment. For higher values of load resistance, arrays based on a delta circuit and parallel connection generated higher maximal values of current than the array based on parallel connection. The array based on a delta circuit generated the highest values of current; from $20 \mathrm{k} \Omega$ to $200 \mathrm{k} \Omega$ depending on experiment. The exemplary values of generated current for a load resistance equal to $50 \mathrm{k} \Omega$ are presented in Figure 13 . 


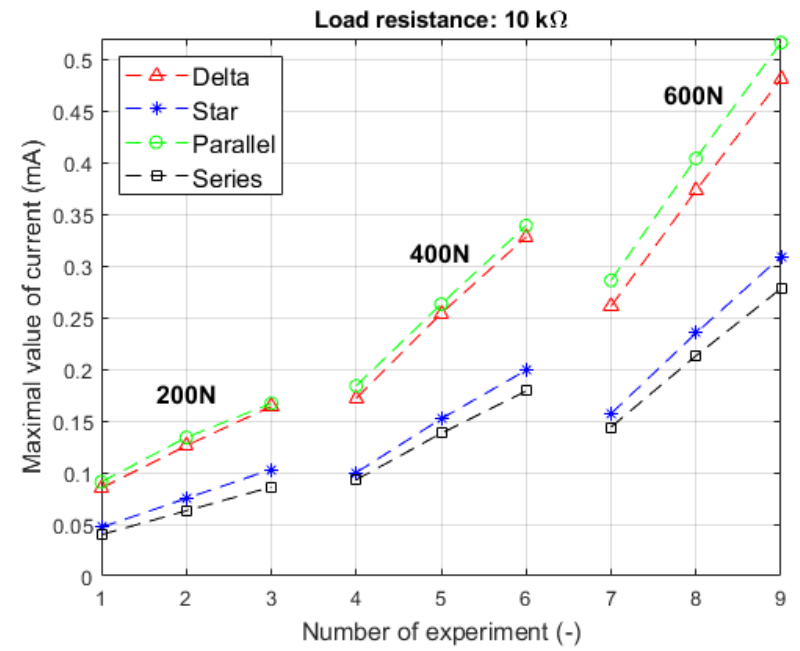

Figure 12. Comparison of maximal values of current for MFC arrays.

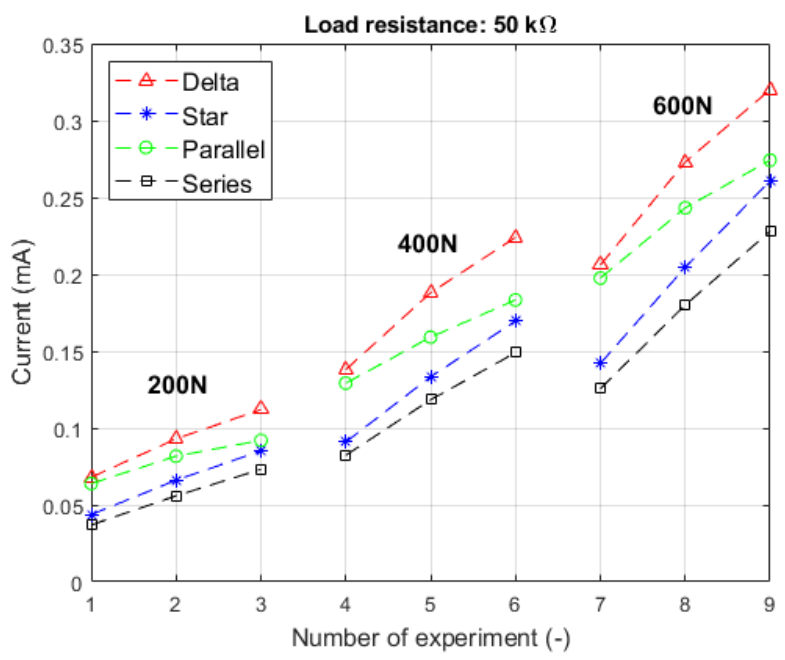

Figure 13. Comparison of current generated by MFC arrays for load resistance equal to $50 \mathrm{k} \Omega$.

The array based on a star circuit generated the highest values of current from $80 \mathrm{k} \Omega$ to $500 \mathrm{k} \Omega$, depending on the experiment.

\section{Conclusions}

Energy harvesting based on the four arrays of MFC patches, which were glued onto a rotating shaft, was tested in laboratory research. The first array was based on a delta circuit of three MFC patches and equipped with a three-phase rectifier; the second array was based on a star circuit of three MFC patches and equipped with three-phase rectifier; the third array was based on a parallel connection of three MFC patches and each MFC patch was equipped with full-bridge rectifier; and the fourth array was based on a series connection of three MFC patches and each MFC patch was equipped with a full-bridge rectifier.

The array based on a delta circuit generated the highest value of maximal electric power in comparison to the rest of the arrays. It was experimentally observed that the arrays equipped with a three-phase rectifier (delta or star circuits of MFC patches) generated higher values of maximal power than the arrays based on the connection of three full-bridge rectifiers connected in parallel or in series.

The array based on parallel connection generated the highest maximal value of current in comparison to the rest of the arrays. However, the array based on parallel connection generated higher values of current in comparison to the rest of the arrays only for low values of load resistance; from $10 \mathrm{k} \Omega$ to $40 \mathrm{k} \Omega$ depending on experiment. For higher 
values of load resistance, arrays based on a delta circuit and a star circuit generated higher maximal values of current than the array based on parallel connection.

Despite the fact that the amount of energy, which is harvested as described in this article on MFC arrays, was very small in comparison to the amount of energy absorbed by an asynchronous motor, energy harvesting can still have a practical application. Harvested energy can be used to supply wireless sensors which are used to measure shaft parameters, e.g., stress. These wireless sensors can replace sensors which require the application of conduits for their power supply, be led through the inside of the rotating shaft, feature the application of slip ring assembly, and be mounted on the shaft end.

Author Contributions: Conceptualization, D.G. and P.M.; methodology, D.G. and P.M.; investigation, P.M. and D.G.; writing-original draft preparation, D.G.; writing—review and editing, D.G.; supervision, D.G. Both authors have read and agreed to the published version of the manuscript.

Funding: This research was funded by the AGH University of Science and Technology within the scope of the research program No. 16.16.130.942 and Initiative for Excellence-Research University at AGH UST.

Institutional Review Board Statement: Not applicable.

Informed Consent Statement: Not applicable.

Data Availability Statement: Data are contained within the article.

Conflicts of Interest: The authors declare no conflict of interest.

\section{References}

1. Wang, Z.; He, L.; Gu, X.; Yang, S.; Wang, S.; Wang, P.; Cheng, G. Rotational energy harvesting systems using piezoelectric materials: A review. Rev. Sci. Instrum. 2021, 92, 041501. [CrossRef]

2. Machado, S.P.; Febbo, M.; Ramírez, J.M.; Gatti, C.D. Rotational double-beam piezoelectric energy harvester impacting against a stop. J. Sound Vib. 2020, 469, 115141. [CrossRef]

3. Guan, M.; Liao, W.H. Design and analysis of a piezoelectric energy harvester for rotational motion system. Energy Convers. Manag. 2016, 111, 239-244. [CrossRef]

4. Kim, G.W. Piezoelectric energy harvesting from torsional vibration in internal combustion engines. Int. J. Automot. Technol. 2015, 16, 645-651. [CrossRef]

5. Yan, L.; Hou, J.; Yang, Z.; Chu, X. Design and experimental characterization of a vibration energy harvesting device for rotational systems. Adv. Mech. Eng. 2013, 5, 263614. [CrossRef]

6. Cheng, C.; Chen, Z.; Xiong, Y.; Shi, H.; Yang, Y. A high-efficiency, self-powered nonlinear interface circuit for bi-stable rotating piezoelectric vibration energy harvesting with nonlinear magnetic force. Int. J. Appl. Electromagn. Mech. 2016, 51, 235-248. [CrossRef]

7. Grzybek, D.; Micek, P. Piezoelectric energy harvesting based on macro fiber composite from a rotating shaft. Phys. Scr. 2019, 94, 095802. [CrossRef]

8. Roundy, S.; Tola, J. Energy harvester for rotating environments using offset pendulum and nonlinear dynamics. Smart Mater. Struct. 2014, 23, 105004. [CrossRef]

9. Yang, B.; Yi, Z.; Tang, G.; Liu, J. A gullwing-structured piezoelectric rotational energy harvester for low frequency energy scavenging. Appl. Phys. Lett. 2019, 115, 063901. [CrossRef]

10. Zhao, L.C.; Zou, H.X.; Yan, G.; Liu, F.R.; Tan, T.; Zhang, W.M.; Peng, Z.K.; Meng, G. A water-proof magnetically coupled piezoelectric-electromagnetic hybrid wind energy harvester. Appl. Energy 2019, 239, 735-746. [CrossRef]

11. Zhang, J.; Fang, Z.; Shu, C.; Zhang, J.; Zhang, Q.; Li, C. A rotational piezoelectric energy harvester for efficient wind energy harvesting. Sens. Actuators A Phys. 2017, 262, 123-129. [CrossRef]

12. Kurt, E.; Cottone, F.; Uzun, Y.; Orfei, F.; Mattarelli, M.; Özhan, D. Design and implementation of a new contactless triple piezoelectrics wind energy harvester. Int. J. Hydrogen Energy 2017, 42, 17813-17822. [CrossRef]

13. Bouzelata, Y.; Kurt, E.; Uzun, Y.; Chenni, R. Mitigation of high harmonicity and design of a battery charger for a new piezoelectric wind energy harvester. Sens. Actuators A Phys. 2018, 273, 72-83. [CrossRef]

14. Zhao, L.C.; Zou, H.X.; Yan, G.; Liu, F.R.; Tan, T.; Wei, K.X.; Zhang, W.M. Magnetic coupling and flextensional amplification mechanisms for high-robustness ambient wind energy harvesting. Energy Convers. Manag. 2019, 201, 112166. [CrossRef]

15. Bai, F.; Song, G.; Dong, W.; Guan, L.; Bao, H. Fan-structure wind energy harvester using circular array of polyvinylidene fluoride cantilevers. J. Intell. Mater. Syst. Struct. 2017, 28, 653-662. [CrossRef]

16. Khameneifar, F.; Arzanpour, S.; Moallem, M. A piezoelectric energy harvester for rotary motion applications: Design and experiments. IEEE ASME Trans. Mechatron. 2012, 18, 1527-1534. [CrossRef] 
17. Na, Y.; Lee, M.S.; Lee, J.W.; Jeong, Y.H. Wind energy harvesting from a magnetically coupled piezoelectric bimorph cantilever array based on a dynamic magneto-piezo-elastic structure. Appl. Energy 2020, 264, 114710. [CrossRef]

18. Ramezanpour, R.; Nahvi, H.; Ziaei-Rad, S. A vibration-based energy harvester suitable for low-frequency, high-amplitude environments: Theoretical and experimental investigations. J. Intell. Mater. Syst. Struct. 2016, 27, 642-665. [CrossRef]

19. Kuang, Y.; Yang, Z.; Zhu, M. Design and characterisation of a piezoelectric knee-joint energy harvester with frequency upconversion through magnetic plucking. Smart Mater. Struct. 2016, 25, 085029. [CrossRef]

20. Fang, S.; Fu, X.; Du, X.; Liao, W.H. A music-box-like extended rotational plucking energy harvester with multiple piezoelectric cantilevers. Appl. Phys. Lett. 2019, 114, 233902. [CrossRef]

21. Priya, S. Modeling of electric energy harvesting using piezoelectric windmill. Appl. Phys. Lett. 2005, 87, 184101. [CrossRef]

22. Yang, Y.; Shen, Q.; Jin, J.; Wang, Y.; Qian, W.; Yuan, D. Rotational piezoelectric wind energy harvesting using impact-induced resonance. Appl. Phys. Lett. 2014, 105, 053901. [CrossRef]

23. Micek, P.; Grzybek, D. Wireless stress sensor based on piezoelectric energy harvesting for a rotating shaft. Sens. Actuators A Phys. 2020, 301, 111744. [CrossRef]

24. Zhang, S.Q.; Li, Y.X.; Schmidt, R. Modeling and simulation of macro-fiber composite layered smart structures. Compos. Struct. 2015, 126, 89-100. [CrossRef]

25. Smart Material-Home of the MFC. Available online: https://www.smart-material.com/MFC-product-mainV2.html (accessed on 5 March 2021).

26. Deraemaeker, A.; Nasser, H.; Benjeddou, A.; Preumont, A. Mixing rules for the piezoelectric properties of macro fiber composites. J. Intell. Mater. Syst. Struct. 2009, 20, 1475-1482. [CrossRef]

27. Syta, A.; Bowen, C.R.; Kim, H.A.; Rysak, A.; Litak, G. Experimental analysis of the dynamical response of energy harvesting devices based on bistable laminated plates. Meccanica 2015, 50, 1961-1970. [CrossRef]

28. Shi, Y.; Hallett, S.R.; Zhu, M. Energy harvesting behaviour for aircraft composites structures using macro-fibre composite: Part I-Integration and experiment. Compos. Struct. 2017, 160, 1279-1286. [CrossRef]

29. Song, H.J.; Choi, Y.T.; Wereley, N.M.; Purekar, A.S. Energy harvesting devices using macro-fiber composite materials. J. Intell. Mater. Syst. Struct. 2010, 21, 647-658. [CrossRef]

30. Liao, Y.; Sodano, H.A. Modeling and comparison of bimorph power harvesters with piezoelectric elements connected in parallel and series. J. Intell. Mater. Syst. Struct. 2010, 21, 149-159. [CrossRef] 